\title{
Sustainable Marine Economic Development in Vietnam in the Period 2011-2018
}

\author{
Hoang Ngoc Phong ${ }^{1}$, Nguyen Cong My ${ }^{2}$, Bùi Thị Thanh $\mathrm{Hoa}^{3}$, Lê Bich Ngoc ${ }^{4}$ \\ ${ }^{1}$ Head of the topic KC 09.26/16-20, Academy of Policy and Development, Vietnam \\ ${ }^{2}$ Secretary of the topic KC 09.26/16-20, Academy of Policy and Development, Vietnam \\ ${ }^{3}$ Vietnam Institute for Development Strategies, Vietnam \\ ${ }^{4}$ Planning Development Institute, Vietnam Union of Science and Technology Associations, Vietnam \\ Correspondence: Hoang Ngoc Phong, Head of the topic KC 09.26/16-20, Academy of Policy and Development, \\ Vietnam.
}

Received: September 24, 2019

doi:10.11114/aef.v6i6.4589
Accepted: October 18, $2019 \quad$ Available online: October 28, 2019

URL: https://doi.org/10.11114/aef.v6i6.4589

\begin{abstract}
This work is to test the hypothesis of sustainable economic development by using a linear structural model. The structural equations in the structural model show that, the social development goals depend on economic growth and environmental protection goals, namely (Social target) $=1.22 *$ (Economic target) $-0.064 *$ (Environment target) and economic development target depend on social development goals and environmental protection goals, namely $($ Economy target $)=1.35 *$ (Social target) $-0.039 *$ (Environment target). The result show that both economic and social development have an adverse environmental impact that will no longer harmonize goals, reflecting the unsustainable marine economic development in the period of 2011-2018. There have many factors of unsustainable marine economic development in period 2011-2018, but mainly is low economic growth efficiency, low labor productivity and the process of urbanization does not truly create a foundation for economic development.
\end{abstract}

Keywords: sustainable marine economy, structural equation model

\section{Introduction}

Vietnam is located in Southeast Asia, covering an area of $331,236 \mathrm{~km}^{2}$. According to the 2019 census, Vietnam has 96.2 million people, of which $34.36 \%$ of the urban population. The Vietnamese territory is divided into 63 administrative units, including provinces and centrally-run cities. Administratively, 28 provinces and centrally-run cities are localities adjacent to the sea, with a natural area of $126,747 \mathrm{~km}^{2}$ equal to $38.26 \%$ of the country's area, see Figure 1.

Vietnam officially recognizes sustainable development as a harmonious development between the goal of economic growth and the goal of social development and the goal of environmental protection, in Decision No. 153/2004 of August 17, 2004, (Vietnam Agenda 21, 2004). 


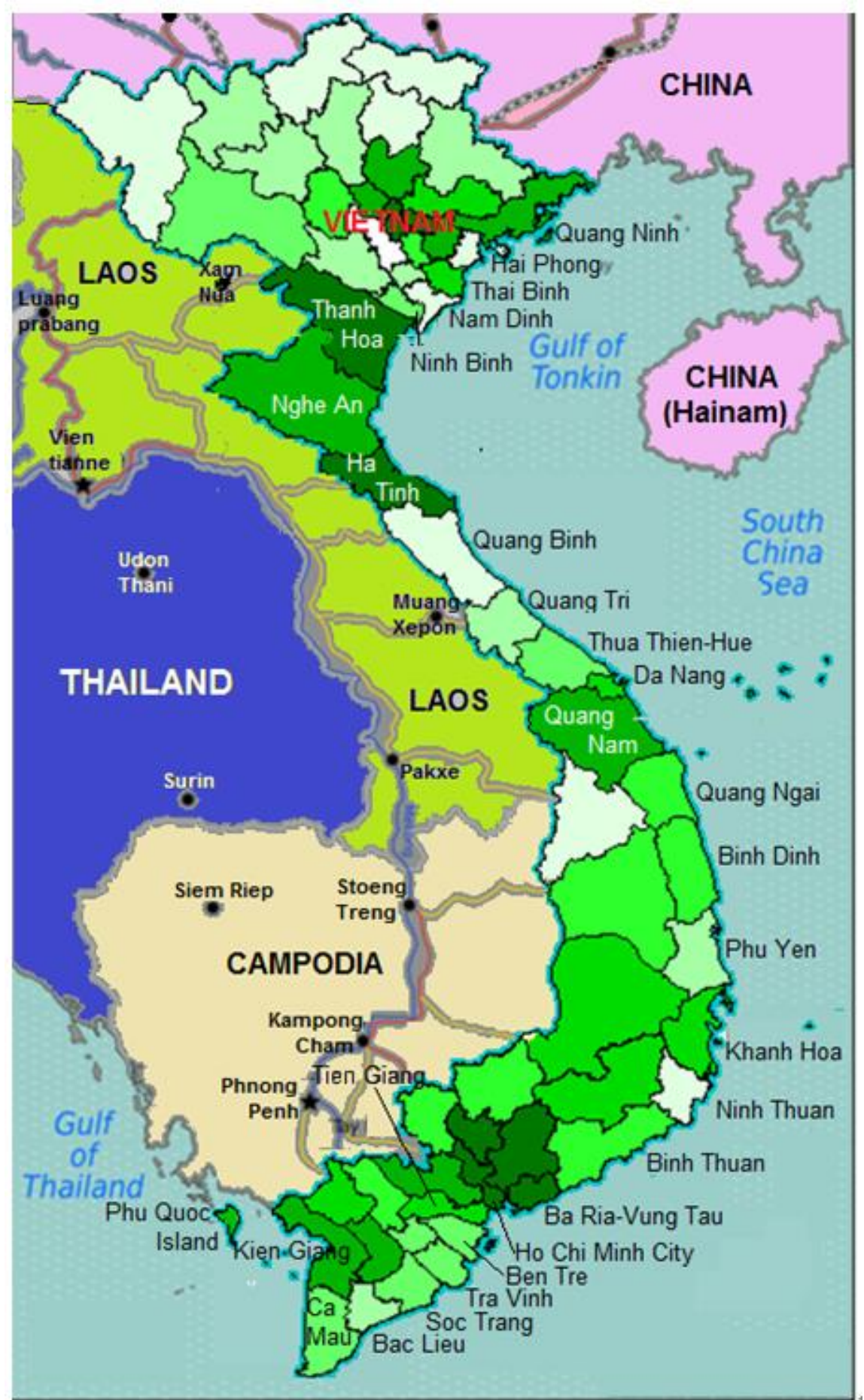

Figure 1. Map of Vietnam and 28 coastal provinces and centrally-run cities

\subsection{Introduce the Problem}

In the context of implementing the 2030 Agenda for Sustainable Development, it was officially implemented by Vietnam in Decision № 622 / QD-TTg dated May 10, 2017 of the Prime Minister. It stated, "Sustainable development is a requirement throughout the process of national development; closely, reasonably and harmoniously combine economic development with social development and protection of natural resources and the environment, proactively responding to climate change", (The Socialist Republic of Vietnam, 2017). Then, the issue of sustainable economic development has become an urgent issue for the coastal areas. 
So far, there has been no official government document that acknowledges sustainable marine economic development. However, it can be understood that sustainable economic development of the sea is similar to that of sustainable development of the whole country, which means that sustainable economic development of the marine economy is understood as harmonizing development among the goals of marine economic growth with the goal of social development in coastal areas and with the goal of protecting the marine environment.

Today, there are many doubts that the above definition of sustainable marine economy is not consistent with the definition of international organizations. So, the objective of this work is to test the hypothesis of sustainable economic development by using a linear structural model, then make discussions about reasons for unsustainable development of marine economy in Vietnam in the period 2011-2018.

This research is important, because it underlies how sustainable development is implemented. When there is no acceptance on the concept of a sustainable marine economy among implementers, so each organization or individual to act in a way according to its own interpretation, difficult to bring about good general results.

\subsection{About Research Hypotheses}

The research hypothesis is the relationship between the three concepts in sustainable marine economic development. The concept of the target of marine environmental protection is expressed by 4 observed indicators, with codes ENV1, ENV2, ENV3 and ENV4. The concept of the target of marine economic growth is expressed by the three observed indicators, ECO1, ECO2, and ECO3. And finally, the concept of social development goals is expressed by three observed indicators, SOC1, SOC2, and SOC3.

The assumptions between the variables and related concepts are presented in Figure 2, where the environmental protection goal is denoted by ENV, the economic growth target is denoted by ECO and the social development goal is denoted by SOC. All three hidden variables ENV, ECO, and SOC are concepts that cannot be directly observed.

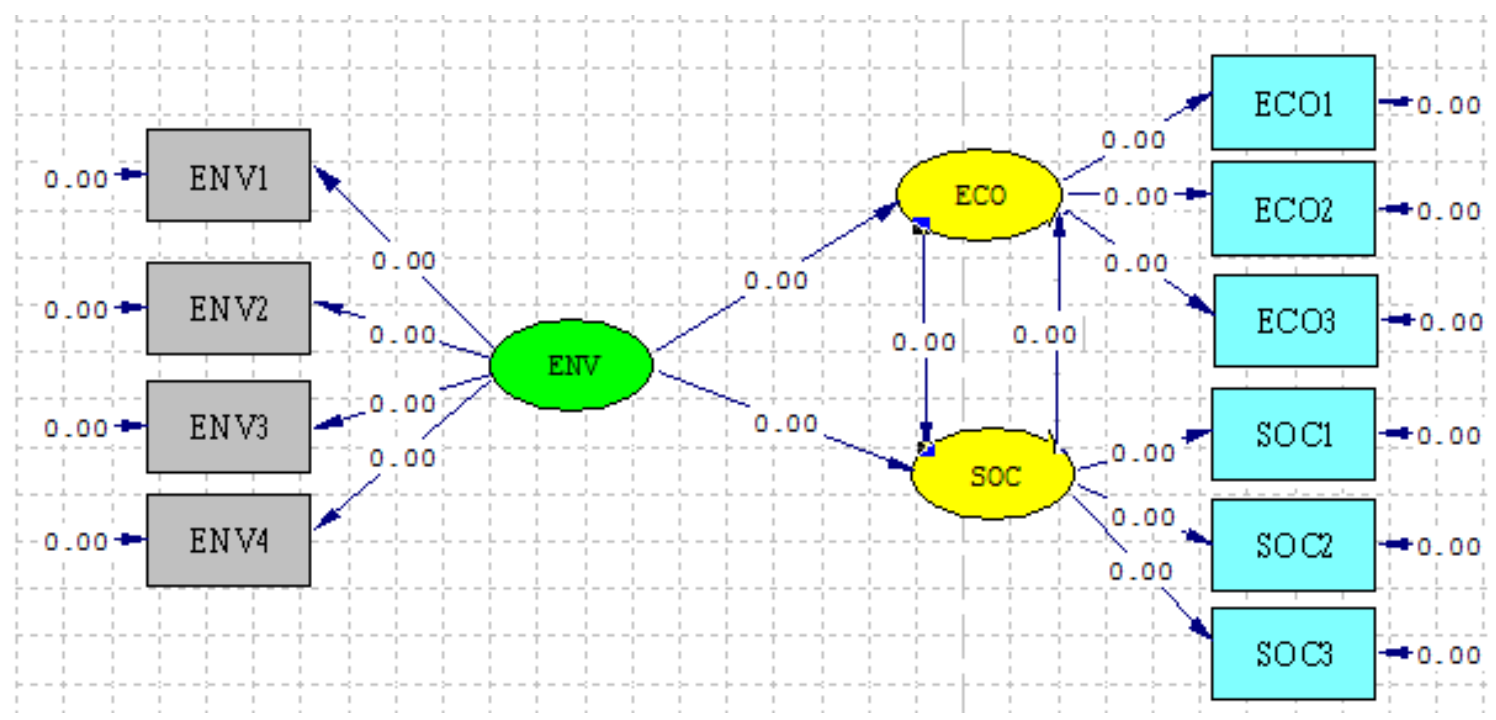

Figure 2. Assumptions about relationships among sustainable marine economic development variables

\section{Research Method}

The model used for this study is a linear structural equation model, abbreviated SEM (the first letter of the three English words Structural equation model). Currently, SEM is one of the most powerful research techniques applied in many fields of study such as biology, economics, education, marketing, management, chemistry as well as social sciences. But this is still a new method for research on sustainable development in Vietnam.

In the world, there have been many research projects applying the SEM model to research on sustainable development. For example, in the study on sustainable development of Bambang Juanda (Bambang Juanda et al., 2005) used the SEM model to select the set of sustainable development indicators for Indonesia. In Vietnam, there have been many research projects to apply SEM model into socio-economy, such as: Thanh Ho Quang, (2018), Tung Diep Thanh, Yen Ngoc Vo Thi (2016).

In fact, there is software supporting SEM model research with linear and non-linear relations, but this work selected linear SEM model. Because the goal of the research is to use quantitative to confirm the qualitative relationship, not 
going into the strong or weak level of the relationships between observed variables and between structural variables, thus using linear SEM model is acceptable.

In this research method, sustainable marine economic development is understood as a relationship with a positive or negative sign. If between the structural variables, there is also a positive sign that is sustainable development, and among the structural variables with a negative relationship, it shows that the marine economic development is not sustainable.

\subsection{Overview of Marine Economic Development in the Period of 2011-2018}

In a recent study by Thai Nguyen Quang, Phong Hoang Ngoc presented a detailed discussion of the concerns of the Party and Government of Vietnam, and analyzed and pointed out the strengths and challenges. Next, authors concerned the six priority marine economic development sectors in the period of 2021-2030. (Thai Nguyen Quang, Phong Hoang Ngoc, et al, 2019). Therefore, the following section will add some achievements and limit from the perspective of sustainable development in the period of 2011-2018, as follows.

In the marine economy, the agriculture, forestry, and fishery (AFF) sector maintain a good growth rate, with the gross region domestic product (GRDP) increasing an average of $7 \%$ per year. The structure of plants and animals is shifted towards improving quality and efficiency, towards responding effectively to climate change, such as sea-level rise. So that, AFF was transferring inefficient rice cultivation land and monoculture rice to shrimp, shrimp - rice. For example, some provinces in coastal area, such as Ca Mau, Kien Giang, Bac Lieu, had been transferring rice to shrimp, shrimp rice, successfully. Other encouraging achievements include increasing the production of farmed shrimp and fish, and exploiting marine food, and increasing the total capacity of marine vessels of 90 horsepower or more. Coastal protection forests are well protected, specialized forests are expanded, increasingly effective in protecting the environment, adapting to climate change - sea level rise. (The Socialist Republic of Vietnam, 2017).

Coastal industry plays an important role in promoting the economic growth of coastal provinces and economic restructuring towards industrialization and modernization. The value added of industry increased by over $8.4 \%$ per year on average in the period of 2010-2018. Industrial production establishments have been gradually invested in building, expanding and upgrading technology and equipment, increasing the quality of goods. Coastal industry had focusing on investment in developing key industries with potential advantages such as agro-fishery processing.

Service industries grew well, moving positively to better meet the needs of production, business, and residential life. Commercial activities meet requirements for production, business, and consumption. The market and supermarket system is interested in investing, basically meeting the buying and selling needs of the people. Export activities of enterprises have many positive changes, contributing significantly to the consumption of agricultural products and the supply of production materials and equipment for other economic sectors, the market is expanded, many aspects. Exports have penetrated the fastidious markets. Such as frozen shrimp and fish have entered the US, Japan, and EU markets. In recent years, infrastructure and tourism products in the coastal provinces and on islands have been invested, upgraded and contributing to improving the quality of tourism services.

The management of natural resources, environmental protection and response to climate change has been paid more attention. Awareness of environmental protection among the people has had many positive changes, the responsibility of state management of environmental protection of all branches and social organizations has been raised; collection rate of municipal solid waste reaches nearly $88 \%$, medical solid waste reaches $97 \%$; strictly control the environment for newly implemented projects; concentrating resources for handling serious environmental pollution points such as garbage and wastewater. Many new technological solutions applied, environmental protection in agriculture has begun to change, gradually reducing the use of chemicals, plant protection drugs, encouraging farmers to clean their fields and collect plant protection drug bottles; Environmental violations are greatly reduced. Projects on sea dikes, sluice gates and saline intrusion, projects on forestation and nature conservation are interested in deploying investment.

The environmental monitoring work was concerned and timely raised the quality of warning information in response to significant damage reduction. Implementing the national target program on climate change response, many coastal provinces have established steering committees; In recent years, focusing on completing documents and scientific bases, promoting communication for people to grasp and understand the impacts caused by climate change. At the same time, step by step associating branch planning and investment projects with climate change scenarios of coastal provinces.

Education and training in coastal provinces continue to develop, quality is improved. The scale and network of education have been developed and expanded; facilities and equipment for teaching and learning have been strengthened, basically meeting the requirements of teaching and learning.

In coastal provinces, people's health care is concerned and strengthened. The quality of medical examination and treatment and preventive medicine work has been constantly improved. Population work-family planning, protection, care for mothers, children and gender equality have improved. The work of food hygiene and safety was focused; 
facilities of production, trading and food processing were regularly inspected, cared for and reminded. Primary health care for children has achieved positive results.

Based on the implementation of the National Program on Gender Equality, coastal provinces have well implemented the objectives set out in the Plan, focusing on issues related to women's rights and interests. Coastal provinces have paid special attention to propaganda and awareness-raising on gender equality through many different forms. Highlights are activities such as training, organizing conferences and contests; communication through the mass media; building pilot models integrated with gender equality programs and projects.

In coastal provinces, cultural and press activities are increasingly rich and diversified; step by step develop and improve the quality. Building cultural environment, social and ethical standards, cultural families achieved some positive results. The education of traditional ethics and Vietnamese family lifestyles is of community interest. The values of traditional culture, customs, and good practices are preserved and promoted.

In coastal provinces, the target programs and policies supporting the poor and poor households in recent years have created positive changes in many aspects, contributing to promoting economic growth and solving many pressing in society. Mechanisms, policies, and projects are integrated to create motivations to promote the implementation of the Program on poverty reduction, gradually raising incomes and improving people's lives.

The implementation of social security policies is considered by the Party committees, authorities and mass organizations in coastal provinces as a central and regular task. Mobilizing social resources to well perform the work of gratitude, gratitude, and care for social policy beneficiaries, people with meritorious services, and social protection beneficiaries.

\subsection{Reasons for Choosing Observed Variables Represent the Concept of Sustainable Development Goals of Marine Economy}

The indicators selected to representing marine economic growth targets, including ECO1 are investment capital per labor (unit: million dong, current price); ECO2 is the ratio of employed workers to the total population (unit :\%); and $\mathrm{ECO} 3$ is the rate of training (unit : \%).

Why choose the 3 indicators above? Because of, the advantage is that the economic indicators, such as ECO2, ECO3, are available in the provincial statistical yearbook, only ECO1 must be calculated from the investment capital and the number of employees working in the cassava economy. All this data is available in the provincial statistical yearbook.

The indicators are selected to representing Social concept, including SOC1 is per capita income per month; SOC2 is the proportion of the urban population; and SOC3 is the proportion of poor households with a multidimensional approach. The point is that all three selected indicators are available in the statistical yearbooks of coastal provinces. In addition, the simple SOC1 indicator shows labor productivity, because if the production scale increases, but the labor productivity does not increase, then the average income per head is unlikely to increase. The SOC2 indicator represents the progress of society because all civilized countries have a high proportion of the urban population. The SOC3 indicator is the multidisciplinary poverty rate. This is an indicator showing a lot of social content, such as equity in income distribution. In fax, if equitably distributed, the poverty rate may be small, although the per capita income of the coastal province is not high. The low rate of poverty is also due to society having many jobs, not leaving workers outside of growth, etc.

Regarding the environment, it is understood as a social environment and natural environment. The indicator showing the concept of the social environment is expressed by the indicator ENV1: Number of prosecuted cases per population (\%). This is a broadly meaning implied indicator, for society with many individuals violating institutions, the high number of prosecuted cases proves that the society has actively made the environment more safety. This ratio is small, showing that the social environment is transparent and clear, everyone is guaranteed and the number of individuals violating institutions will be reduced.

Indicators expressing the concept of the natural environment, including ENV2 are the total capacity of fishing ships with a capacity of $90 \mathrm{HP}$ or more. According to Vietnamese regulations, fishing vessels with a capacity of 90 horsepower (HP) or more are allowed to go offshore to fish. Therefore, this indicator reflects offshore fishing, having a direct impact on the marine environment. The ENV3 indicator is the fishing output compared to the total fishing and aquaculture production (unit \%); ENV4 indicator is the proportion of aquaculture compared to the total fishing and aquaculture production (units \%). The ENV 1 to ENV4 directly affects the marine economic environment.

The scale of applied indicator includes two types, one is to use the natural unit of measurement as mentioned above, including $\%$, monetary unit million dong per labor, and investment capital of billion. Second, normalized indicators return an index with a scale greater than or equal to zero (0) and less than or equal to one (1). Standardize by the formula: Standardized indicator $i=\left(\mathrm{U}_{\mathrm{i}}-\mathrm{Min}_{\mathrm{i}}\right) /\left(\mathrm{Max}_{\mathrm{i}}-\mathrm{Min}_{\mathrm{i}}\right)$. Where $\mathrm{U}_{\mathrm{i}}$ is the value of observations of indicator $i, \min _{\mathrm{i}}$ 
is the smallest value of observations of indicator $i$ and $\operatorname{Max}_{\mathrm{i}}$ is the largest value of observations of indicator $i$ in the period 2010-2018.

The maximum reasonable estimation is done by LISREL software, the estimation results are of two types, the first is to evaluate the validity of the measurement model, using Chi-square test, model removal probability (Pr), the freedom of the model and finally the general reliability of the model.

Second, confirmatory factor analysis (CFA), which explains the path coefficients; next the appropriateness of structural models $\left(\mathrm{R}^{2}\right)$, the direct, indirect and total impacts.

\section{SEM Model Estimation Results and Comments}

\subsection{The Results}

The estimation results of the SEM model, presented in Figure 3 and Figure 4 show that the model is of quite good quality: Firstly, the probability of eliminating a small model (P-value $=0.00000)$; and two, the errors of the model is small (RMSEA $=0.008)$.

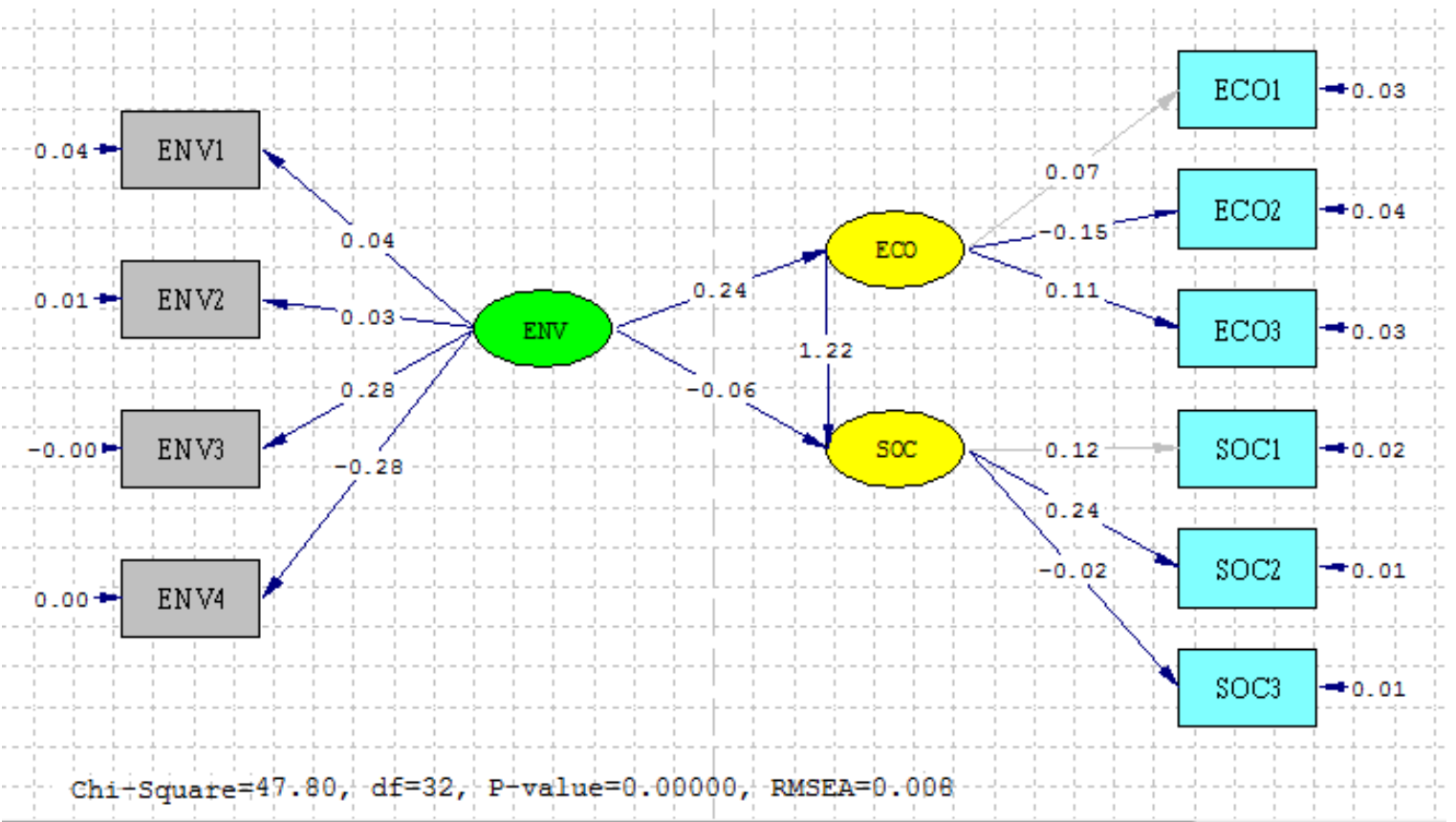

Figure 3. SEM model estimation results

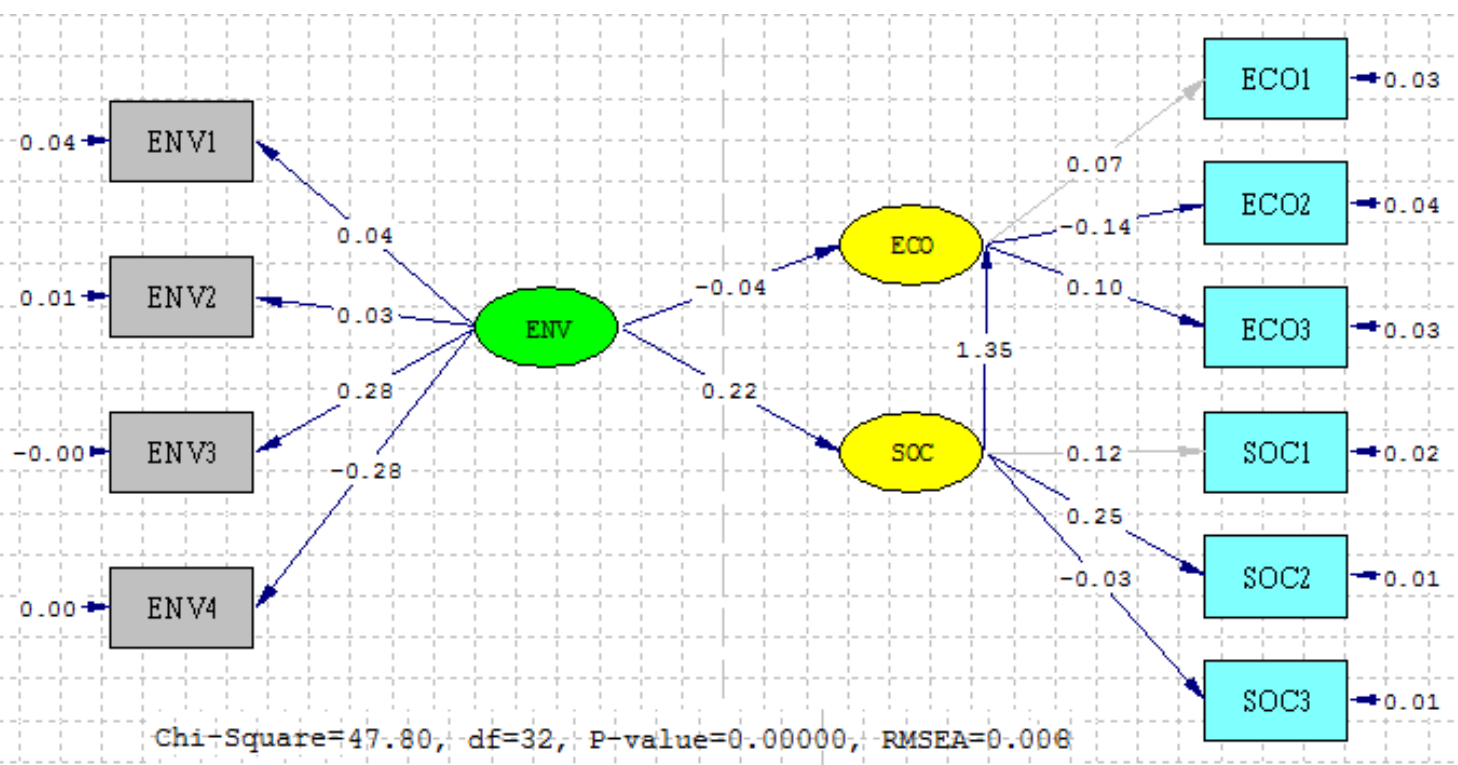

Figure 4. SEM model estimation results 
The difference between the estimation results presented in Figure 3 and Figure 4 is that the relationship between the two endogenous, economic and social variables. In Figure 3, the arrow goes from economic to social. In Figure 4, the arrow goes from social to economic.

The estimation results of the SEM model also show that this model has 32 degrees of freedom, the Chi-Square test value $=47.8$, Chi-square/df $=1.49$, for 252 observations, the coefficient shows that the model is acceptable. As such, the model is consistent with the collected research data.

The relationship between observed variables and the conceptual variables shown in Figure 3 and Figure 4 is summarized in Table 1 as follows:

Table 1. Summary of estimated coefficients

\begin{tabular}{|c|c|c|c|c|}
\hline Variable code and variable name & $\begin{array}{l}\text { Linear regression equation } \\
\text { (standardized data) }\end{array}$ & $\begin{array}{c}\text { Error of } \\
\text { variable }\end{array}$ & $\mathbf{R}^{2}$ & $\begin{aligned} \mathbf{N}_{-}^{0} \\
\text { Figure }\end{aligned}$ \\
\hline \multirow{2}{*}{ ECO1: investment capital per labor } & $\mathrm{ECO} 1=0.075^{*} \mathrm{ECO}$ & 0.016 & 0.463 & 3 \\
\hline & $\mathrm{ECO} 1=0.070 * \mathrm{ECO}$ & 0.016 & 0.463 & 4 \\
\hline \multirow{2}{*}{$\begin{array}{l}\text { ECO2: the ratio of employed workers to the total } \\
\text { population }\end{array}$} & $\mathrm{ECO} 2=-0.15 * \mathrm{ECO}$ & 0.026 & 0.534 & 3 \\
\hline & $\mathrm{ECO} 2=-0.14 * \mathrm{ECO}$ & 0.026 & 0.534 & 4 \\
\hline \multirow{2}{*}{ ECO3: the percentage of trained workers } & $\mathrm{ECO} 3=0.11 * \mathrm{ECO}$ & 0.006 & 0.336 & 3 \\
\hline & $\mathrm{ECO} 3=0.100 * \mathrm{ECO}$ & 0.006 & 0.336 & 4 \\
\hline \multirow{2}{*}{ SOC1: the average monthly income per capita } & $\mathrm{SOC} 1=0.12 * \mathrm{SOC}$ & 0.019 & 0.829 & 3 \\
\hline & $\mathrm{SOC} 1=0.12 * \mathrm{SOC}$ & 0.019 & 0.829 & 4 \\
\hline \multirow{2}{*}{ SOC2: the proportion of the urban population } & $\mathrm{SOC} 2=0.24 * \mathrm{SOC}$ & 0.001 & 0.890 & 3 \\
\hline & $\mathrm{SOC} 2=0.25 * \mathrm{SOC}$ & 0.001 & 0.890 & 4 \\
\hline \multirow{2}{*}{$\begin{array}{l}\text { SOC3: the proportion of poor households with } \\
\text { multi-dimensional access }\end{array}$} & SOC $3=-0.025 * \mathrm{SOC}$ & 0.008 & 0.674 & 3 \\
\hline & SOC3 $=-0.026 * \mathrm{SOC}$ & 0.008 & 0.674 & 4 \\
\hline $\begin{array}{l}\text { ENV1: Number of prosecuted cases compared to the } \\
\text { population }\end{array}$ & $\mathrm{ENV} 1=0.040 * \mathrm{ENV}$ & 0.036 & 0.624 & $3 \& 4$ \\
\hline $\begin{array}{l}\text { ENV2: The total capacity of fishing ships with a } \\
\text { capacity of } 90 \text { horse powers or more }\end{array}$ & $\mathrm{ENV} 2=0.031 * \mathrm{ENV}$ & 0.013 & 0.732 & $3 \& 4$ \\
\hline $\begin{array}{l}\text { ENV3: catches in relation to total catches and } \\
\text { aquaculture. }\end{array}$ & $\mathrm{ENV} 3=0.28 * \mathrm{ENV}$ & 0.000 & 0.970 & $3 \& 4$ \\
\hline $\begin{array}{l}\text { ENV4: the proportion of aquaculture compared to } \\
\text { the total exploitation and aquaculture output. }\end{array}$ & $\mathrm{ENV} 4=-0.28 * \mathrm{ENV}$ & 0.000 & 0.980 & $3 \& 4$ \\
\hline \multicolumn{5}{|l|}{ Structural equations } \\
\hline \multirow{2}{*}{\multicolumn{2}{|c|}{$\begin{array}{l}\mathrm{SOC}=1.22 * \mathrm{ECO}-0.064 * \mathrm{ENV} \\
\mathrm{ECO}=1.35 * \mathrm{SOC}-0.039 * \mathrm{ENV}\end{array}$}} & 0.143 & 0.732 & 3 \\
\hline & & 0.141 & 0.759 & 4 \\
\hline
\end{tabular}

Source: Statistical data (see appendix C) and estimates using LISREL software

Table 1 summarizes the coefficients that show that all four observed variables closely related to the marine environment (such as high-value R2), proving that the observations variables have been presenting the marine environment nature. Of which, three are positively associated with the environmental concept variable (ENV), which means that the quality of the environment better as the measure of these variables increases. Particularly ENV4 variable has a negative relationship. It means that to harmonize with the environmental protection goal, we need to reduce the scale of aquaculture. This proves that aquaculture has exceeded the self-cleaning environment. To expand the scale, it is necessary to apply new science-technical measures into aquaculture.

The next, three observed variables expressing the concept of economic goals, the variable ECO1 (capital per labor) is positively related to the economic goals. Because increasing capital to labor will boost labor productivity. It is one of the three theoretical points of macroeconomics, "how to produce", the other two theoretical points are the production of "what" and "for whom".

The ECO3 indicator (the percentage of trained workers), also has a positive relationship with economic growth. Because the proportion of trained labor reflects the quality of labor, it is a direct and indirect product of training, bringing science and creativity into economic growth.

Particularly, the ECO2 indicator (the ratio of employed workers to the total population) is negatively related to the goal of economic growth. In fact, this indicator reflects the aging of the population. The ratio of labor to the total population of coastal provinces is currently quite high, called the golden population period. However, if the golden population is suitable for economic growth, it is very convenient, but the economic growth does not meet the employment requirements of the workers, then the golden population may be a tragedy. In fact, there has been a phenomenon of excessive labor and underemployment in recent years, which has caused difficulties for the coastal areas. 
In general, the coefficients of linear relationships between the marine economic growth target and the observed variables, although estimated in Figure 3 or Figure 4, have the same sign of a relationship, but the coefficients are different, but not big.

Among the three observed variables expressed social development goals, whether estimated in Figure 3 or Figure 4, have the same sign of relationship. In particular, indicators SOC1 (per capita income per month) and indicators SOC2 (proportion of the urban population) are positively related. Because, SOC1 represents the outcome of the production process, showing the progress of society; and SOC2 indicator represents a civilization in the development process. SOC3 (the percentage of poor households with multidimensional access) has a negative relationship with the social development goals, but this is a reasonable relationship because the society is progressive and civilized, the lower the rate of poor households.

Finally, the structural equations in the structural model show that, if estimated from Figure 3 or Figure 4, the results are very different. As estimated in Figure 3, the social development goals depend on economic growth and environmental protection goals, namely SOC $=1.22 *$ ECO $-0.064 *$ ENV. It shows that social development also has a negative impact on the marine environment.

If estimated in Figure 4, the economic growth target is a dependent variable on social development and environmental protection goals, namely ECO $=1.35 * \mathrm{SOC}-0.039 * \mathrm{ENV}$. It shows that economic growth target also has a negative impact on the marine environment.

Thus, the structural model has shown that economic growth goals and social development goals are inversely related to environmental protection, reflecting the unsustainable marine economic development in the period of 2011-2018.

\subsection{Statistics and Data Analysis}

Our research data was secondary and selected from the annual statistical yearbook (2010-2018) of 28 coastal provinces and cities. This data is publicly available. (Provincial Statistical yearbook, 2010-2018).

The data used is panel data, taken from the Statistical Yearbook of coastal provinces published from 2010 to 2018, a total of 280 observations (equal to 10 years x 28 provinces), after dropped observations without enough data for all 9 selected indicators, the remaining 252 observations were calculated. The authors used LISREL software to build covarial models and estimates.

The software calculates the relationship between observed indicator and the concept variables with a small coefficient $\mathrm{R} 2$, for two reasons. One is to use panel data; secondly, the selected observed indicator do not best reflect the content of the concept variables. For example, in order to show the goal of economic growth, it is necessary to select supply and demand factors, such as private and government consumption, exports and imports. But at present, there are no observational data on the demand side indicators, so this study only takes some indicators of the supply side such as investment per labor and the percentage of employed workers who have been trained.

\section{Discussion: The Causes of Unsustainable Marine Economic Development in Vietnam}

As analyzed above, it shows that the development of marine economy in the period of 2011-2018 is unsustainable, due to the following subjective reasons.

\subsection{Low Economic Growth Efficiency}

Unsustainable marine economic development is due to low growth efficiency.

In Vietnam, in the period of 2011-2018, marine economic growth depends heavily on investment, but investment efficiency is low. One of the evaluation criteria is the ICOR coefficient, calculated from the statistical data of 28 coastal provinces, the ICOR period 2011-2015 is 5.4, the period 2016-2018 is 6.5.

ICOR figures for coastal area shows that, if excluding the difference in technology level, in the period of 2011-2018, the efficiency of investment capital in the marine area are quite highly. Meanwhile, according to experience, for countries in the period of rapid growth with low technological level, for example, in period 1970-1981, ICOR of South Korea only equal 3.3 or 4.0 in period 1978-1987, 4.4 in period 1988-1992 (Gillis M., Perkins D. H, et al, 1996). The above analysis results show that the efficiency of social investment in coastal area in the period 2011-2018 is still quite low.

\subsection{Low Labor Productivity}

Unsustainable marine economic development is due to low labor productivity. The labor productivity (comparative price 2010, Table 2) of the four key economic regions is not much higher than the national average, even the labor productivity of the key economic region or the key economic region of the Mekong Delta shows lower performance. If converted in foreign currencies directly, the key economic region has the highest labor productivity $(9,000$ USD per 
labor), this level is only equal to $76 \%$ of the labor productivity of Thailand, $27 \%$ of Malaysia and only $8.7 \%$ Korean in 2010. (ASEAN statistics yearbook 2010).

Table 2. Labor productivity (at constant 2010 prices)

\begin{tabular}{|l|c|c|c|c|c|}
\hline & 2010 & 2015 & 2016 & 2017 & 2018 \\
\hline Coastal area (Million VND/labor) & 71.25 & 133.34 & 141.33 & 151.82 & 163.08 \\
\hline whole country (Million VND/labor) & 51.01 & 87.83 & 90.67 & 98.63 & 107.29 \\
\hline
\end{tabular}

Source: Calculated from data of statistical yearbook of coastal provinces

\subsection{The Process of Urbanization Does not Truly Create a Foundation for Economic Development}

In 8 years (2010-2018), the urban population of the four key economic regions increased to about 2.6 million people, but of which some urban areas and urban population increased mainly by administrative decisions, bringing farmers became urban residents. The number of people becoming townspeople is estimated at 64-65 thousand people, equal to the urban population of Hai Phong city in 2008. This is also one of the reasons leading to the budget of the concentrated cities too big for infrastructure construction without investing to support the development of businesses.

At present, most of the urban areas in key economic regions are unbalanced in terms of infrastructure, water supply, sewerage, electricity supply, health facilities, education ... overloading compared to the population size. For example, in Hanoi, after the rain, there were 50-60 points of inundation due to poor drainage, about 5\% of the housing area was of very poor quality, the indiscriminate use of water led to a loss rate of up to $40 \%$. (Author handing from Provincial statistical yearbooks).

\subsection{The Problem of Environmental Pollution Has a Significant Impact on Life}

Along with rapid economic development, the problem of environmental pollution in cities, tourist centers, craft villages in rural areas of the key economic regions is increasing, causing significant impacts on living standards, persons and sustainable development, requiring urgent resolution. Because of, as follows:

- In coastal cities, due to the impact of urbanization and the movement of a large part of the population from rural areas to urban areas, the urban population is already overloaded compared to the infrastructure. The floor causes serious pollution from garbage and water sources, only Ho Chi Minh City alone, discharges about 6,000 tons of waste every day; dust concentration exceeds the permitted standard up to 1.13 to 1.31 times, etc. Most of the big cities such as Hue, Da Nang, Ho Chi Minh City, ... the phenomenon of rainwater inundation in each heavy rain causes the sewage in the sewers to spill on the streets, causing water pollution, ground, and air.

- Many centers and industrial complexes polluting wastewater into rivers and coastal areas are quite serious, for example along the Thi Vai town, the downstream area of Dinh River is polluted due to untreated sewage, treatment or handling is not thorough; Quang Ninh area polluted by mine wastewater and oil scum due to travel by ships and shipbuilding enterprises ... has reached an alarming level.

\section{Conclusion}

In general, this article is not detailed and the level of accuracy is still low, because of there is no specialized data set for this research purpose, but it cannot wait for ever. However, it opens a new direction of applying structural models to sustainable development research in Vietnam. This is very suitable for training on sustainable studies and especially Universities in Vietnam.

SEM model is also used in the environmental analysis in Vietnam less. The above is an example of application, although there are some limitations such as the set of observation indicators reflecting the economy is not considerately reliable, the $\mathrm{R}^{2}$ coefficient of some indicators is still lower then 0.5. However, this example will facilitate further sustainability studies using the SEM model. The estimation results also show that the relationship between the concept variables is very close to each other, and consistent with the selected data (the $\mathrm{R}^{2}$ of structure equations are high, both above 0.73 ).

Through this quantitative study, data on the marine environment is very lacking, especially data on indicators reflecting marine environmental pollution such as plastic bags, wastewater from coastal cities, from Untreated coastal industry.

The results of the SEM model have confirmed that the marine economic development in the period 2011-2018 is not sustainable. This study is still simple; however, it will inform policy makers to pay more attention to sustainable marine economic development.

From this analysis, the policy implication is that the offshore fishing vessels should not be increased unless to apply science and technology solutions are suitable for the coastal context. At the same time, it is not advisable to encourage 
aquaculture more if there are no scientific measures to expand the carrying capacity. Currently, economic growth does not meet the needs of jobs, for sustainable development, economic growth must be faster.

Both economic and social development have an adverse environmental impact that will no longer harmonize goals, implying that the policy here is to accompany economic development with increased monitoring and impact assessment project, expansion of economic and social capacity. When grown beyond carrying capacity of the marine environment, it will have an adverse impact on the environment.

\section{References}

ASEAN Statistical Yearbook. (2010). Jakarta: ASEAN Secretariat. December 2010.

Bambang, J., \& Upik, R. W. (2005). Selection and modelling of sustainable development indicator: Indonesia case. Retrieved from ekonomi.fem.ipb.ac.id/doc/jurnal9.pdf

Gillis, M., \& Perkins, D. H. et al. (1996). Economic of development. New York.

Provincial Statistical yearbook. (2010-2018). Publishing house Thong ke.

Thai, N. Q., \& Phong, H. N. et al. (2019). Analysis of Inter-Regional Relationship between Vietnam Coastal Zones and the Rest of Vietnam. Theoretical Economics Letters, 9, 1594-1614. https://doi.org/10.4236/tel.2019.95102

Thanh, H. Q. (2018). Survey the availability of online public services of the business community in Lam Dong province. Science magazine of Dalat University, 8(1S).

The Socialist Republic of Vietnam. (2017). Decision No. 622 / QD-TTg promulgating the national action plan to implement the 2030 agenda for sustainable development.

Tung, D. T., \& Yen, N. V. T. (2016). Factors affecting student satisfaction and engagement through evaluating the quality of Tra Vinh University service. Journal of Economics - Culture - Education, 22, July 2016.

\section{Copyrights}

Copyright for this article is retained by the author(s), with first publication rights granted to the journal.

This is an open-access article distributed under the terms and conditions of the Creative Commons Attribution license which permits unrestricted use, distribution, and reproduction in any medium, provided the original work is properly cited. 